\title{
ENGLISH AS AN INTERACTIONAL RESOURCE FOR DOING BEING ACADEMICALLY \\ COMPETENT: STUDENT PRACTICES IN GROUP
} MEETINGS

\author{
ELISABETH DALBY KRISTIANSEN
}

\section{ABSTRACT}

An increasing number of Nordic university programmes are offered in English. Consequently, students are expected to carry out academic activities in English rather than the local language. Through ethnomethodological conversation analysis of video recordings of student project group meetings, this article explores how students orient to English in their everyday academic and linguistic practices, focusing on students' orientations to language proficiency and language choice as resources for displaying academic competence and literacy.

\section{[1] INTRODUCTION}

In a growing number of Nordic degree programmes, the language of teaching and learning is English, either by official decision or de facto. Hence, students are expected to be able to attend lectures, do project work, and write reports in English rather than in the local language.

A significant body of research studies this development, looking into institutional policies and ideologies (e.g. Altbach \& Knight, 2007; Jenkins, 2014; Ljosland, 2011; Tange, 2012) and student and staff attitudes to internationalisation (e.g. Jensen, Denver, Mees, \& Werther, 2013; Jensen \& Thøgersen, 2011; Vinke, Snippe, \& Jochems, 1998). Further, several studies describe how such policies affect not only the attitudes but also the performance of students and staff in internationalised universities (e.g. Airey, 2010; Haberland et al., 2008; Thøgersen \& Airey, 2011), addressing possible consequences of English-medium teaching for pedagogical and teaching standards. However, studies that focus on the attitudes, experiences and practices of students in internationalised universities rarely topicalise academic activities (Airey \& Linder, 2008), focusing instead on linguistic aspects of internationalisation, for instance language norms (Söderlundh, 2013) or on English as a lingua franca (Björkman, 2011; 
Mortensen, 2010). A few studies focus on students' use of English as a method for doing being international students (Hazel \& Mortensen, 2013; Mortensen, 2014) or on students' academic activities in two languages (Airey, 2010) but these are the exception rather than the rule.

This study aims to fill the gap indicated above by addressing student practices in relation to academic activities in internationalized settings. Specifically, the study focuses on the question of whether and how university students use English as a resource for doing being academically competent, i.e. for how they constitute themselves in interaction as academically competent persons (Sacks, 1984). Detailed analyses of interactions in student project group meetings explore academic competence and literacy as participants' concerns manifested in students' orientations to language choice and language proficiency in their local, ongoing interactions. The analyses show 1) how students mostly treat language as a private matter which is not to be commented on despite deviations from native-speaker norms and 2) how students in some circumstances do orient to language as a resource for displaying academic competence and literacy by treating matters of linguistic correctness, such as e.g. grammar, using the right words and collocations, etc., as relevant to the activity at hand. In that way, the analyses document a discrepancy between institutional requirements which state that English is the language of teaching and learning practices and actual student practices. Therefore, the study adds to the growing body of research on internationalized university practices by investigating how students adapt and adopt English as part of their daily work as students.

In line with Garfinkel (1967) and the framework of Ethnomethodology, the study takes an emic perspective (Pike, 1967) on student practices and academic activities. The analyses focus on how the students present themselves as academically competent participants. Sacks' phrase doing being (see above) is thus central because it treats personal characteristics, jobs that are done, and the like (Sacks, 1984, p. 414) as accomplished in interaction and thus as achievements. Other terms used in the study convey essentially the same perspective, e.g. displaying - when participants make themselves recognizable as doing being e.g. academically competent - and demonstrating - when participants show that they master a specific type of activity, e.g. formulating a research question, by competently performing or participating in that activity (Mondada, 2011; Sacks, 1992). In the next section the notions of competence and literacy, which are central for the analytical endeavours of this study, are introduced and discussed from an ethnomethodological perspective. 
[2] ACAdEMic COMPETENCE AND Literacy: An EThNomethodologiCAL PERSPECTIVE

In line with Garfinkel (1967), competence is understood as the unnoticed and enforceable right of collectivity members to claim the ability to carry out the mundane tasks in and through which social organization is accomplished. In short, competence is a method by which we recognise others as fellow members and make ourselves recognisable as members as well. Hence, displays of competence constitute the constant though unnoticed work of members to establish and maintain social order (Rawls, 2008). However, competence is also infinitely specific because it is related to membership which may be of society in general, but may also be more specific as in membership of a profession, a political group or an academic field. For instance, Goodwin (1994) demonstrates how archaeologists' discursive practices constitute socially organized ways of seeing and categorizing the world related to their distinctive interests. Similarly, academic practices constitute socially organized ways of organizing the world: so academic competence is a member's right and ability to carry out tasks that recognizably contribute to and rely on these specific practices. In consequence, a student's relevant participation in e.g. academic discussions or processes of formulating a research question constitutes displays of academic competence since they recognizably demonstrate their right and ability to participate in these practices.

Displays of competence can be carried out by means of resources such as facial expressions, gestures, manipulation of objects, language, etc. In academia, many displays of competence rely specifically on members' mastery of writing and written language. Often, this type of competence is discussed in terms of literacy (e.g. Gee (2008); Heath (1983); see also New Literacy Studies, e.g. Hamilton and Barton (1994); Lea and Street (2006); Street (1984)). For the purposes of this study, academic literacy is understood as members' practices for doing being recognizably competent within a specific academic activity, such as e.g. formulating a research question, and in relation to an academic community of practitioners, for instance discourse analysts or engineers, by means of linguistic resources related to reading and writing (Kristiansen, 2015).

\section{[3] DATA AND METHODS}

The study employs Ethnomethodology and Conversation Analysis (EMCA). EMCA describes how participants accomplish and maintain common understanding in interaction, focusing on the understandings and orientations which participants make publicly available for each other in and through the interaction and which are consequently available for inspection by the analyst (Wooffitt \& 
Hutchby, 1998). Accordingly, students' displays of academic competence to their co-participants and co-participants' orientations to displays of competence as displays of competence take centre stage. These are explored through sequential analysis (Garfinkel \& Sacks, 1986; Sacks, Schegloff, \& Jefferson, 1974): participants' understanding of each turn is established by means of their responses to the turn. In that way, the analyses trace participants' displays of and orientations to academic competence as they happen by and for the participants in the local, ongoing interaction.

The analyses presented in this article are based on video recordings of group meetings of four student groups, in total approximately 30 hours of recorded data. The meetings are recurrent, unsupervised events, taking place over a period of one semester, at which students meet to discuss the progress of their project and plan further tasks. Such meetings have a formal structure, and they usually, though not always, take place on campus. The students participating in the meetings are enrolled in internationalised bachelor (BA) programs at Danish universities. Hence, all teaching takes place in English and student activities are expected to be conducted in English, even though the majority of teachers and students are native speakers of Danish.

\section{[4] LANGUAge CHOICE AND PROFICIENCY AS RESOURCES FOR DisPlay-} ING ACADEMIC LITERACY

The student group meetings take place in institutional settings in which the default working language is English. Nevertheless, participants orient to language choice as an interactional resource and use it for various interactional purposes (cf. Mortensen, 2014). In the data, however, language choice or proficiency is rarely treated by the participants as relevant for the interaction. Overall, they focus on the content of what is said rather than on the form, treating language as a non-topic in the interaction. This is in line with Firth $(1996,2009)$ who demonstrates that non-native speakers who communicate using English as a lingua franca in workplace settings do conversational work to treat lingua franca talk as normal and ordinary, using e.g. the let it pass strategy and the make it normal strategy to treat grammatical, syntactic, vocabulary, and similar anomalies as transparent and meaningful contributions to the interaction. Similarly, the students treat linguistically anomalous contributions as ordinary and meaningful - in other words, they are not commented on by the speaker or other participants. In some circumstances, however, students do orient to language as a resource for displaying academic competence and literacy. In the following, two examples of this will be discussed: a) students' choice of language during group meetings, and b) students' formulating activities. 


\section{[4.1] Language choice in student group meetings}

Overall, analysis of the data reveals two different practices concerning language choice in the group meetings. Two groups use both English and Danish during group meetings, treating the choice of language as a purely pragmatic matter, despite institutional requirements and even group policies stating that the language of group meetings is English. The two other groups consistently use English during group meetings, and any use of Danish is marked by the speaker as dispreferred by means of e.g. hesitations, restarts, and the like. Below, analyses of two examples of language alternation demonstrate how these different orientations to language choice are played out in the local interaction of student group meetings.

Language choice as a purely pragmatic decision

For the group in example (1) below, English is one linguistic resource among others, and the choice of language depends mainly on local affordances and requirements such as the activity at hand, the proficiency of the participants, etc.

(1)

1 John: vil i ik nok [hver gang i sender en mail til os] 'would you please every time you send a mail to us'

2 Nana: [når vi ikke engang selv ka huske hva vi hedder] 'when we can't even remember ourselves what we are called'

3 John: så skriv GRUPPEnummer 'then write the group number'

4 PPP: (0.4)

5 John: ¡øverst]

'at the top'

6 Nana: [jo]

'yeah'

7 PPP: $\quad(0.3)$

((Werner enters the room))

8 John: ik [os]

'right?'

9 Nana: [hva gr]uppe [num]mer er vi egentlig 'which group number are we actually?'

10 Werner: [und-] 'sor-'

11 Werner: und 「skuld] 


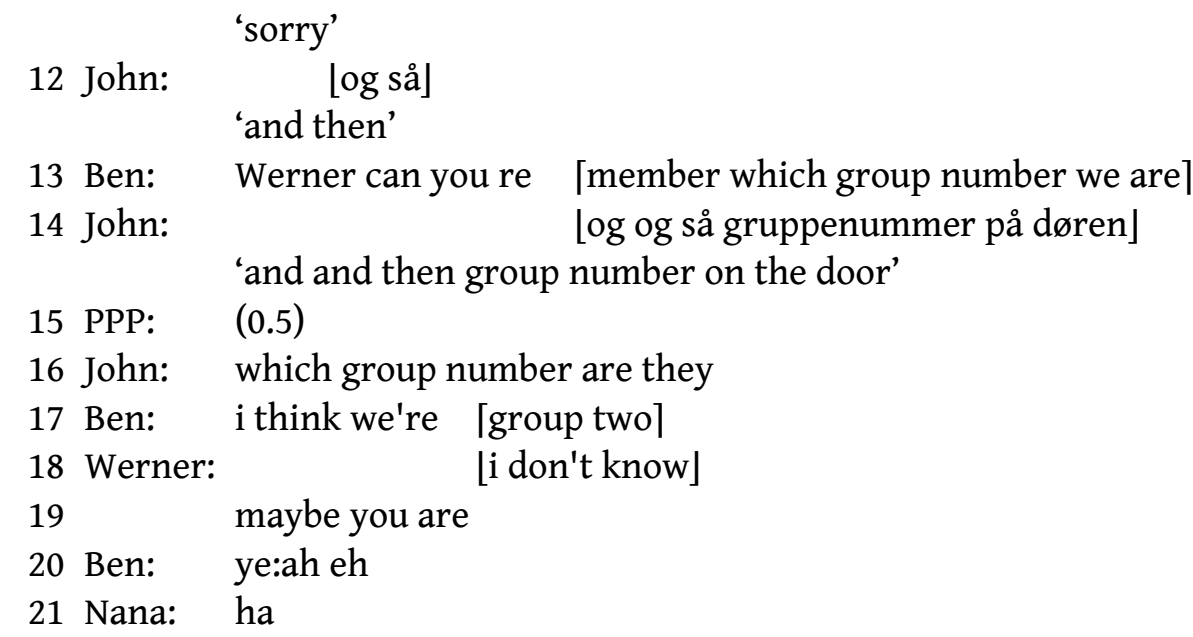

In the example above, a student group is about to start a meeting with their supervisors. One supervisor, John, is present while the other supervisor, Werner, enters the room in line 7, completing the group expected to participate in the meeting. All the students and John are native speakers of Danish while Werner is a native speaker of German. Werner also speaks Danish, and all participants speak English as a second language. John is telling the students to always include their group number in emails. His turns are in Danish as are the student Nana's responding turns. John is about to finish his instruction when Werner enters the room (line 7). After entering, Werner initiates an apology, using the Danish word undskyld (line 10). Werner's choice of the Danish word displays an orientation to the language currently being used and at the same time demonstrates some knowledge of Danish. John (lines 12 and 14) continues the group number topic in Danish. In overlap with his turn, however, the student Ben addresses Werner in English, asking if he knows the group's number (line 13). Having finished his directions to the group, John also addresses Werner (line 16), and like Ben he uses English for this. Werner answers in English, aligning with the language alternation performed by Ben and John. From this point, the meeting is exclusively in English.

The language alternation is not commented on or otherwise oriented to by the participants who thus treat it as normatively appropriate in the situation (Hazel \& Mortensen, 2013). The speaker's choice of English rather than Danish displays his orientation to the language scenario (Mortensen, 2013): a non-native speaker has entered, and he is selected as the recipient of the turn, and this makes relevant a change of language from Danish to English. At the same time, Werner's entrance changes the participation framework (Goffman, 1981) by completing the group assembled for the meeting, making relevant a transition from 
pre-meeting talk to the meeting itself, which is institutionally required to take place in English. The language choice here thus reflects local, turn-by-turn considerations of speaker proficiency as well as type of activity, including relevant institutional requirements. In fact, the language of the rest of the meeting, following the language change in example 1, is English. This is due to the presence of the supervisors, since the group otherwise conducts all its meetings in Danish.

Language choice as a relevant resource for displaying academic competence

The group in example (2) below treats English as the preferred, normatively required language of their meetings. The use of other languages, especially Danish, is oriented to as dispreferred as evidenced by the hedgings, pauses, hesitations, etc. (cf. Pomerantz, 1984) which accompany the few language alternations that take place during these meetings. Further, this group treats proficiency in English as a relevant resource for doing being academically competent in the activity at hand.

(2)

1 Sif i don't think it would be wrong to say something like (.)

$2 \quad$ it it $\searrow$ øh

3

(1.0) øh::m

'eh::m'

4

altså øh jam-switching

'well eh but'

5 Ann: hhh $\lceil\mathrm{hm} \mathrm{m} \mathrm{hm}\rceil$

6 Sif: $\quad$ [altså det opstod] (.) det \opstod $\backslash ø h m:$

'well it originated it originated ehm'

$7 \quad$ (1.3) det opstod altså på grund $\mathrm{af} \rightarrow$ 'so it originated because of'

8 på grund af nogle ting der skete i den \tid $>\mathrm{ik}$ 'because of some things that happened at that time right'

Sif: ((turns head slowly toward Ann; gazes at Ann))

Lars: $\quad(($ looks at Sif))

9 PPP: (0.9)

Sif: $\quad$ ((gazes at Ann))

Ann: ((nods slightly))

10 Sif: som et et lissom et billede på tiden $\rightarrow$ 'like a like a picture of the time'

Sif: $\quad$ ((gazes at Ann)) 
Ann:

((nods))

11 Sif

og d-
'and th-'

Sif:

((turns head; gazes at Lars))

12 Sif:

(0.4) på $\nearrow \mathrm{DEN}$ tid but is $\nearrow$ still $^{1}$ now $\searrow$

'of that time'

13 PPP:

(2.9)

14 Sif:

kan i se hvad jeg $>$ mener

'can you see what i mean?'

15 Ann: -ja_-

In example 2, Sif initiates a formulating sequence (these will be described in more detail in section 3.2 below). But the very first element of the formulation, $i t$, is followed by a series of filled and unfilled pauses (lines 2-3) instead of the relevant next part of the formulation. Next, Sif produces two Danish adverbs altså and jam- (line 4) which project explanations or accounts. The last of these is discontinued as Sif utters switching, a meta-comment which categorises her contribution as uttered in another language than English. The clause which follows is produced in Danish and accomplishes the formulation of a concept, et billede på tiden (lines 6-10). In her continuation of the turn, still in Danish, Sif projects a second part of the concept with og $d$ - (line 11). She cuts it off in midword, however, and restarts the turn, this time using English. Despite the language alternation, however, Sif retains the concept that she has formulated in Danish, treating it as an untranslatable, i.e. as a concept formulated in Danish for which she, in the local interaction, does not want to or is not able to produce a corresponding English term (lines 11-12).

Sif thus treats the use of Danish as a dispreferred action, a choice that is made only after a series of delays and hesitation markers which indicate an unsuccessful word search (M. H. Goodwin, 1983; M. H. Goodwin \& Goodwin, 1986). The language alternation enables her to achieve progressivity in the turn and to formulate a concept, but as soon as the concept has been formulated, Sif returns to the preferred language, despite retaining the concept in Danish. In other words, Sif orients to the normative expectation that participation in discussions in group meetings requires the use of English, demonstrating that for this group of students, proficiency in English is a relevant resource for doing being academically competent in the sense of contributing relevantly to group

[1] Sif uses the English word "still" with the meaning of the English adverb as an equivalent of the Danish "stadig". The gist of the turn is something like "what the problem is is that it is a picture of that time but it is still around today". 
discussions.

\section{[4.2] Formulating activities in student group meetings}

The students generally focus on the content of the participants' turns rather than on the linguistic form, so that grammatical errors, atypical use of words and other deviations from native-speaker conventions are not made relevant by the participants in the interaction. However, in formulating activities, proficiency in English as well as practices for writing and knowledge of genre conventions are oriented to as relevant to the academic activity at hand. The students display academic literacy, orienting to practices related to language use as relevant for their displays of academic competence and discussing how to phrase their research question, how words and expressions relate to particular scholarly approaches, etc.

During formulating activities, the students formulate research questions for their semester project. Example 3 below presents a fragment of one such formulating activity. One participant is formulating a possible research question. The speaker uses a special prosodic format for displaying doing formulating, namely the Writing Aloud Voice (Kristiansen, 2015, 2017). During Writing Aloud Voice (WAV) sequences, speakers sound as if they were reading aloud from a text - but in fact they are composing a text. WAV sequences consist of three elements: 1) a quotative, i.e. a pronoun plus a reporting verb or construction which introduces the sequence and projects a change of footing (Goffman, 1981), making a formulation the next relevant element in the turn; 2) a WAV clause, i.e. one single turn constructional unit, which is produced using the WAV prosodic format and which comprises the linguistic material that is formulated; and 3) an unquote which constitutes a return to the previous footing.

(3)

\begin{tabular}{|c|c|}
\hline Jan: & i think eh: something like that but \\
\hline 2 & (0.2) maybe (.) we could $\Delta$ say something like $\Delta$ \\
\hline 3 & (0.4) to what $\varnothing-\mathrm{eh}$ \\
\hline 4 & (0.6) i don't know (.) which eh prepos- preposition to: \\
\hline 5 & to use here but \\
\hline 6 & (0.3) TO or IN or something (.) what identity (0.3) eh: \\
\hline 7 & $(2.8)$ \\
\hline 8 & does $(0.3)$ the discour- \\
\hline 9 Bo: & $(($ cough $))$ \\
\hline 10 Jan: & the yeah the various discourses of social darw- \\
\hline 11 & darwin (.) nism \\
\hline 12 & something like that \\
\hline
\end{tabular}


13

14

15 PPP:

16 Jan:

17
$(0.3)$

\section{eh:: subject the \reader}

(0.5)

because that's what they that's what they eh use in in eh power relations and and eh Foucault and Fairclough and

In example 3, Jan initiates a formulating sequence with the quotative maybe we could say something like (line 2), and he begins the WAV clause, that is, the actual formulation with to what (line 3). After these two words, however, Jan interrupts the formulation process in order to account for his choice of preposition (lines 4-5). In the account, Jan treats correct use of language as an accountable matter in this particular activity. First, he orients to language as relevant for the activity; second, the self-repair of the preposition displays Jan's monitoring of his own linguistic performance during the WAV sequence; third, Jan's use of the word preposition (line 4) displays his ability to talk about language as a theoretical entity; and fourth, his self-repair prepos- preposition (line 4) in which the first vowel of the word is changed from the Danish version of it to something that is heard as more English orients to English as the preferred language of the activity at hand.

After the account, Jan continues the formulation process and completes the WAV clause (lines 6-14). The WAV clause reaches completion despite an abundance of pauses and other delays in the progressivity of the turn. In other circumstances such delays might be heard as inviting participation by other speakers, but in WAV sequences, speakers are allowed to finish the WAV sequence on their own. One reason for this is the sequential format of WAV sequences. The change in footing accomplished by the introductory quotative and the changed prosody combined with the syntactic and sequential unity of the WAV sequence create a space in which the speaker can search for words and tinker with the formulation without interruption from other participants (Kristiansen, 2015, 2017).

The WAV clause ends with a clearly falling intonation and is followed by a pause in which it would be possible for the other participants to show agreement. But this does not happen, so Jan begins an unquote in which he accounts for the suggested formulation. Only the beginning of the account is included here.

Jan states that this particular formulation is suitable because it uses language employed by important researchers within the relevant academic field (lines 16-17). In this way, he displays academic literacy by demonstrating his ability to consciously use language in a specific way which makes him recognisable as doing being a competent member of a specific academic community 
of practitioners.

Example 3 thus demonstrates that students orient to language, in the sense of academic register, as a relevant resource for displaying academic literacy. Moreover, Jan oriented briefly to language in the sense of proficiency in English during his account for the preposition (lines 4-5); but this is not just a passing concern, as demonstrated in the continuation of the discussion in example 4 below:

(4)

\begin{tabular}{|c|c|}
\hline 28 Ann: & can you say it again $>$ Jan \\
\hline 29 PPP: & $(1.3)$ \\
\hline 30 Jan: & how (.) or (.) ehheh \\
\hline 31 & $(1.6)$ \\
\hline 32 & i don't know the preposition to use but \\
\hline 33 & in what eh identity does \\
\hline 34 & $(0.5)$ eh:: \\
\hline 35 & (0.6) eh:: social darwinism (.) subject the reader \\
\hline 36 PPP: & $(1.0)$ \\
\hline 37 Ane: & in what $>$ iDENtity \\
\hline 38 Jan: & yeah that's that \\
\hline 39 PPP: & $(0.7)$ \\
\hline 40 Jan: & that's not really the way to put it \\
\hline
\end{tabular}

Example 4 opens with Ane's response to Jan's unquote which began in line 16 and ends immediately before the opening of example 4 . Ane requests a repetition of Jan's previous turn (line 28), and Jan complies (lines 30-35), producing a second version of the research question. This second WAV sequence is not initiated by a quotative, since it is done in response to a request, and it contains fewer delays, since it has been produced once before. Once again, Jan interrupts the WAV clause after the initial word to account for his choice of preposition (line 32). He thus once more treats the choice of preposition as an accountable matter. Nevertheless, Ane's response to Jan's proposed research question (line 37) consists of an other-initiation of repair of that very part of the research question. She singles out in what identity as a repairable (Schegloff, Jefferson, \& Sacks, 1977) despite Jan's accounts for this in both WAV sequences. Ane's otherintiation of repair treats language correctness as an accountable matter and as something that is relevant to the interaction.

Jan's response (lines 38-49) in turn demonstrates how he understands Ane's response. His initial yeah displays alignment with Ane's turn and he continues with that's that which further demonstrates agreement with the categorization 
of in what identity as incorrect as implied in Ane's turn. After a pause, Jan continues by clarifying his understanding of the problem (line 40): that's not really the way to put it. Jan thus treats Ane's repair initiation as ordinary and relevant. Thus, both participants treat language and linguistic correctness as a relevant and accountable matter in the formulating activity. In other words, knowledge of English grammar, usage, etc. is a relevant resource for competently participating in the academic activity of doing formulating a research question.

\section{[5] DISCUSSION AND CONCLUSION}

Firth (2009) discusses English used as a lingua franca in terms of a distinction between language as a private matter and a public matter - as something that can be commented on or not. In a related discussion, Day (2003) establishes a difference between orienting to a language as owned or unowned - that is, whether speakers treat a language, in this case English, as a lingua franca where anything goes or whether they orient to it as English as the native speakers use it.

For the most part, in the data presented here, language is treated as a private matter, one that is not to be commented on by others despite formal anomalies and other deviations from native-speaker norms. However, in formulating activities, it seems that language is a public matter, available for comment and repair. Further, in most of the meeting activities, participants treat English as unowned, i.e. as a lingua franca without externally established norms and regulations, by systematically not commenting on deviations from native-speaker norms. But during formulating activities, participants orient to English not as a lingua franca where anything goes, but as a language that is owned by its native speakers. They want it to be correct in the sense of nativespeaker-like: grammatically correct, using the right words, collocations and sometimes even pronunciation.

The students' change of orientation to English during formulating activities suggests that they treat the formulation proposed during WAV sequences as different from the surrounding talk. This may be linked to the status of the WAV clause as a potential text. If the WAV clause is understood as talk that has been tentatively textualised, students' heightened awareness of and orientation to formal linguistic details in such sequences suggests that they regard spoken language, even in formal meeting contexts, as unowned, private lingua franca usage whereas written language is regarded as owned and as a public matter that can and should be discussed to ensure the correctness and appropriateness of the text. Moreover, this suggests that for the student groups in the data, proficiency in and knowledge of English become relevant resources for displaying 
academic competence only in activities related to production of textual material. In non-textual academic activities, such resources are not relevant for doing being academically competent.

The study demonstrates that students' language practices vary considerably between groups as well as within groups depending on the activity at hand. Language choice and proficiency are not oriented to as relevant methods for displaying academic competence except in very specific activities. In some groups, language choice is treated as irrelevant to the activity at hand, even when there is an evident discrepancy between institutional requirements and actual practice. The data thus suggests that the institutional implementation of English as the language of teaching and learning is not necessarily reflected in student practices; further, students' limited, activity-specific orientation to academic literacy poses a challenge to the potential for language learning which is often assumed to be an inherent benefit of internationalization.

As a consequence, one might also wonder about the longterm consequences of introducing English as the language of teaching and learning in higher education. Does internationalization automatically result in higher proficiency? What kind of proficiency will the students develop by interacting in groups such as the ones described in this study? Will students orient to English (or other languages of internationalization) as owned or unowned? And, consequently, will they become more proficient in the sense of more correct? Perhaps the more relevant question in this connection is: are students expected to become more proficient, in the sense of more correct, by graduating from internationalized university programs? If that is the case, perhaps educators need to consider methods for changing students' orientation to academic literacy so that language choice, language proficiency and other aspects of academic literacy are understood as relevant aspects of a broader range of academic activities.

\section{REFERENCES}

Airey, John. 2010. The ability of students to explain science concepts in two languages. Hermes-Journal of Language and Communication Studies, 45, 35-49.

Airey, John \& Cedric Linder. 2008. Bilingual scientific literacy? The use of English in Swedish university science courses. Nordic Journal of English Studies, 7(3), 145-161.

Altbach, Philip G. \& Jane Knight. 2007. The internationalization of higher education: Motivations and realities. Journal of Studies in International Education, 11(3-4), 290-305. doi:10.1177/1028315307303542 
Björkman, Beyza. 2011. Pragmatic strategies in English as an academic lingua franca: Ways of achieving communicative effectiveness? Journal of Pragmatics, 43(4), 950-964. doi:https://doi.org/10.1016/j.pragma.2010.07.033

Day, Dennis. 2003. Owning a language and lingua franca discourse. In Alan Firth (Ed.), Language Travels: A Festschrift for Torben Vestergaard, 77-88. Aalborg: Institut for sprog og internationale kulturstudier, Aalborg Universitet.

Firth, Alan. 1996. The discursive accomplishment of normality: On 'lingua franca'English and conversation analysis. Journal of Pragmatics, 26(2), 237-259. doi:https://doi.org/10.1016/0378-2166(96)00014-8

Firth, Alan. 2009. Doing not being a foreign language learner: English as a lingua franca in the workplace and (some) implications for SLA. IRALInternational Review of Applied Linguistics in Language Teaching, 47(1), 127-156. doi:10.1515/iral.2009.006

Garfinkel, Harold. 1967. Studies in Ethnomethodology. Englewood Cliffs, NJ: Prentice Hall.

Garfinkel, Harold \& Harvey Sacks. 1986. On formal structures of practical actions. In H. Garfinkel (Ed.), Ethnomethodological studies of work, 160-193. London: Routledge.

Gee, James Paul. 2008. Social linguistics and literacies: Ideology in discourses. London, New York: Routledge.

Goffman, Erving. 1981. Forms of talk. Philadelphia: University of Pennsylvania Press.

Goodwin, Charles. 1994. Professional vision. American Anthropologist, 96(3), 606633. doi:10.1525/aa.1994.96.3.02a00100

Goodwin, Margery Harness. 1983. Searching for a word as an interactive activity. In Semiotics 1981, 129-137. New York: Plenum Press.

Goodwin, Margery Harness \& Charles Goodwin. 1986. Gesture and coparticipation in the activity of searching for a word. Semiotica: Journal of the International Association for Semiotic Studies/Revue de l'Association Internationale de Sémiotique, 62(1-2), 51-76. doi:10.1515/semi.1986.62.1-2.51

Haberland, Hartmut, Janus Mortensen, Anne Fabricius, Bent Preisler, Karen Risager \& Susanne Kjærbeck (eds.). 2008. Higher Education in the Global Village: Cultural and Linguistic Practices in the international University. Roskilde: 
Department of Culture and Identity, Roskilde University.

Hamilton, Mary \& David Barton. 1994. Worlds of literacy (Vol. 5). Clevedon: Multilingual Matters Limited.

Hazel, Spencer \& Janus Mortensen. 2013. Kitchen talk-Exploring linguistic practices in liminal institutional interactions in a multilingual university setting. In Hartmut Haberland, Dorte Lønsmann, \& Bent Preisler (Eds.), Language Alternation, Language Choice and Language Encounter in International Tertiary Education, 3-30, Springer.

Heath, Shirley Brice. 1983. Ways with words: Language, life and work in communities and classrooms. Cambridge: Cambridge University Press.

Jenkins, Jennifer. 2014. English as a Lingua Franca in the International University: The Politics of Academic English Language Policy. Abingdon, New York: Routledge.

Jensen, Christian, Louise Denver, Inger M. Mees \& Charlotte Werther. 2013. Students' attitudes to lecturers' English in English-medium higher education in Denmark. Nordic Journal of English Studies, 12(1), 87-112.

Jensen, Christian \& Jacob Thøgersen. 2011. Danish University lecturers' attitudes towards English as the medium of instruction. Ibérica, 22, 13-33.

Kristiansen, Elisabeth Dalby. 2015. Student displays of academic competence in the international university. (Ph.D.), University of Southern Denmark, Odense.

Kristiansen, Elisabeth Dalby. 2017. Doing formulating: "Writing Aloud Voice" sequences as an interactional method. Journal of Pragmatics, 114, 49-65. doi:http://doi.org/10.1016/j.pragma.2017.04.002

Lea, Mary R. \& Brian V. Street. 2006. The" academic literacies" model: Theory and applications. Theory Into Practice, 45(4), 368-377. doi:http://dx.doi.org/10.1207/s15430421tip4504_11

Ljosland, Ragnhild. 2011. English as an academic lingua franca: Language policies and multilingual practices in a Norwegian university. Journal of Pragmatics, 43(4), 991-1004. doi:https://doi.org/10.1016/j.pragma.2010.08.007

Mondada, Lorenza. 2011. Understanding as an embodied, situated and sequential achievement in interaction. Journal of Pragmatics, 43(2), 542-552. doi:10.1016/j.pragma.2010.08.019 
Mortensen, Janus. 2010. Epistemic stance marking in the use of English as a lingua franca: A comparative study of the pragmatic functions of epistemic stance marking in problem-solving sequences at student project group meetings, with special emphasis on meetings where English is used as a lingua franca. (Ph.D.), Roskilde University,

Mortensen, Janus. 2013. Notes on English used as a lingua franca as an object of study. Journal of English as a Lingua Franca, 2(1), 25-46. doi:https://doi.org/10.1515/jelf-2013-0002

Mortensen, Janus. 2014. Language policy from below: Language choice in student project groups in a multilingual university setting. Journal of Multilingual \& Multicultural Development, 35(4), 425-442. doi:http://dx.doi.org/10.1080/01434632.2013.874438

Pike, Kenneth L. 1967. Language in relation to a unified theory of the structure of human behavior. The Hague: Mouton \& Co., Publishers.

Pomerantz, Anita. 1984. Agreeing and disagreeing with assessments: some features of preferred/dispreferred turn shapes. In J. Maxwell Atkinson \& John Heritage (eds.), Structures of social action: Studies in conversation analysis, 57101. Cambridge, Paris: Cambridge University Press, Editions de la Maison des Sciences de l'Homme.

Rawls, Anne Warfield. 2008. Harold Garfinkel, ethnomethodology and workplace studies. Organization Studies, 29(5), 701-732. doi:10.1177/0170840608088768

Sacks, Harvey. 1984. On doing "being ordinary". In J. Maxwell Atkinson \& John Heritage (eds.), Structures of Social Action, 413-429. Cambridge: Cambridge University Press.

Sacks, Harvey. 1992. Lectures on conversation, volume II. Oxford: Blackwell Publishing.

Sacks, Harvey, Emanuel A. Schegloff \& Gail Jefferson. 1974. A simplest systematics for the organization of turn-taking for conversation. Language: Journal of the Linguistic Society of America, 696-735. doi:10.2307/412243

Schegloff, Emanuel A., Gail Jefferson \& Harvey Sacks. 1977. The preference for self-correction in the organization of repair in conversation. Language: Journal of the Linguistic Society of America, 53, 361-382. doi:10.2307/413107

Street, Brian V. 1984. Literacy in theory and practice (Vol. 9). Cambridge: Cam- 
bridge University Press.

Söderlundh, Hedda. 2013. Language choice and linguistic variation in classes nominally taught in English. In Hartmut Haberland, Dorte Lønsmann, \& Bent Preisler (eds.), Language alternation, language choice and language encounter in international tertiary education, 85-102. Dordrecht: Springer.

Tange, Hanne. 2012. Organising language at the international university: Three principles of linguistic organisation. Journal of Multilingual and Multicultural Development, 33(3), 287-300. doi:http://dx.doi.org/10.1080/01434632.2012.661735

Thøgersen, Jacob \& John Airey. 2011. Lecturing undergraduate science in Danish and in English: A comparison of speaking rate and rhetorical style. English for Specific Purposes, 30(3), 209-221. doi:https://doi.org/10.1016/j.esp.2011.01.002

Vinke, Adriana A., Joke Snippe \& Wim Jochems. 1998. English-medium Content Courses in Non-English Higher Education: a study of lecturer experiences and teaching behaviours. Teaching in Higher Education, 3(3), 383-394. doi:http://dx.doi.org/10.1080/1356215980030307

Wooffitt, Robin \& Ian Hutchby. 1998. Conversation Analysis: Principles, Practices and Applications. Cambridge: Polity Press. 
APPENDIX：TRANSCRIPTION CONVENTIONS

The transcription conventions are based on the conventions developed by Gail Jefferson (e.g. 2004). The symbols below, not included in the reference, are also used:

\begin{tabular}{|c|c|c|}
\hline Description & Symbol & Example \\
\hline Rising intonation & $\nearrow$ & $\operatorname{det} \lambda$ opstod \\
\hline $\begin{array}{l}\text { Continuing intona- } \\
\text { tion }\end{array}$ & $\rightarrow$ & ১øhm: \\
\hline Falling intonation & $\searrow$ & get out of \it \\
\hline $\begin{array}{l}\text { Accelerated speech } \\
\text { WAV prosody }\end{array}$ & $\begin{array}{l}\Delta \Delta \\
\text { bold }\end{array}$ & $\begin{array}{l}\text { we could } \Delta \text { say something like } \Delta \\
\text { in what eh identity }\end{array}$ \\
\hline
\end{tabular}

TABLE 1: Additional transcription symbols

Elisabeth Dalby Kristiansen

University of Southern Denmark

elkr@sdu.dk 